\title{
Deficient mismatch repair and $R A S$ mutation in colorectal carcinoma patients: a retrospective study in Eastern China
}

\author{
Xiangyan Zhang ${ }^{1,2}{ }^{\text {, Wenwen Ran }}{ }^{1}$, Jie Wu ${ }^{1}$, Hong Li ${ }^{1}$, Huamin Liu ${ }^{3}$, Lili Wang ${ }^{1}$, Yujing Xiao ${ }^{1}$, Xiaonan \\ Wang ${ }^{1}$, Yujun Li ${ }^{1}$, Xiaoming Xing ${ }^{\text {Corresp. } 1}$ \\ ${ }^{1}$ Department of Pathology, Affiliated Hospital of Qingdao University, Qingdao, China \\ 2 Department of Pathology, Qingdao University Basic Medicine College, Qingdao, China \\ 3 Department of Oncology, Affiliated Hospital of Qingdao University, Qingdao, China \\ Corresponding Author: Xiaoming Xing \\ Email address: edithxing@126.com
}

Objectives: To investigate the frequency and prognostic role of deficient mismatch repair (dMMR) and RAS mutations in Chinese patients with colorectal carcinoma.

Methods: Clinical and pathological information from 813 patients were reviewed and recorded. Expression of mismatch repair proteins was tested by immunohistochemistry. Mutation analyses for RAS gene were performed by real-time polymerase chain reaction. Correlations of mismatch repair status and RAS mutation status with clinicopathological characteristics and disease survival were determined.

Results: The overall percentage of dMMR was $15.18 \%$ (121/797). The proportion of dMMR was higher in patients $<50$ years old $(p<0.001)$ and in the right side of the colon $(p<$ 0.001 ). Deficient mismatch repair was also associated with mucinous production ( $p<$ 0.001 ), poor differentiation ( $p<0.001)$, early tumor stage $(p<0.05)$ and bowel wall invasion ( $p<0.05$ ). The overall RAS mutation rate was $45.88 \%$, including $42.56 \%$ (346/813) KRAS mutation and 3.69\% (30/813) NRAS mutation (including 3 patients with mutations in both). KRAS mutation was significantly associated with mucinous production $(p<0.05)$, tumor stage $(p<0.05)$ and was higher in non-smokers $(p<0.05)$ and patients with a family history of colorectal carcinoma ( $p<0.05$ ). Overall, 44.63\% (54/121) dMMR tumors harbored KRAS mutation, however, dMMR tumors were less likely to have NRAS mutation. Moreover, dMMR, KRAS and NRAS mutation were not prognostic factors for stage I III colorectal carcinoma.

Conclusions: This study confirms that the status of molecular markers involving mismatch repair status and RAS mutation reflects the specific clinicopathological characteristics of colorectal carcinoma. 
1 Deficient mismatch repair and $\boldsymbol{R} A S$ mutation in colorectal carcinoma patients:

2 a retrospective study in Eastern China

3

4 Xiangyan Zhang, ${ }^{1,2^{*}}$ Wenwen Ran, ${ }^{1 *}$ Jie Wu, ${ }^{1}$ Hong Li, ${ }^{1}$ Huamin Liu, ${ }^{3}$ Lili Wang, ${ }^{1}$

5 Yujing Xiao, ${ }^{1}$ Xiaonan Wang, ${ }^{1}$ Yujun Li, ${ }^{1}$ Xiaoming Xing ${ }^{1}$

61 Department of Pathology, Affiliated Hospital of Qingdao University, 16 Jiangsu Road,

7 Qingdao, 266000, China

82 Department of Pathology, Basic Medicine College, Qingdao University, 38 Dengzhou Road,

9 Qingdao, 266000, China

103 Department of Oncology, Affiliated Hospital of Qingdao University, 16 Jiangsu Road, Qingdao,

11266000 , China

12 * These authors contributed equally to this work.

13 Correspondence to: Xiaoming Xing, M.D. Department of Pathology, Affiliated Hospital of

14 Qingdao University, 16 Jiangsu Road, Qingdao, China, 266000

15 E-mail address:edithxing@126.com

16

\section{ABSTRACT}

Objectives: To investigate the frequency and prognostic role of deficient mismatch repair (dMMR) and $R A S$ mutations in Chinese patients with colorectal carcinoma.

Methods: Clinical and pathological information from 813 patients were reviewed and recorded. Expression of mismatch repair proteins was tested by immunohistochemistry. Mutation analyses for $R A S$ gene were performed by real-time polymerase chain reaction. Correlations of mismatch repair status and $R A S$ mutation status with clinicopathological characteristics and disease survival were determined.

Results: The overall percentage of dMMR was 15.18\% (121/797). The proportion of dMMR was higher in patients $<50$ years old $(\mathrm{p}<0.001)$ and in the right side of the colon $(\mathrm{p}<0.001)$. 
differentiation $(\mathrm{p}<0.001)$, early tumor stage $(\mathrm{p}<0.05)$ and bowel wall invasion $(\mathrm{p}<0.05)$. The overall $R A S$ mutation rate was $45.88 \%$, including $42.56 \%$ (346/813) KRAS mutation and $3.69 \%$ (30/813) NRAS mutation (including 3 patients with mutations in both). KRAS mutation was significantly associated with mucinous production $(\mathrm{p}<0.05)$, tumor stage $(\mathrm{p}<0.05)$ and was higher in non-smokers $(\mathrm{p}<0.05)$ and patients with a family history of colorectal carcinoma $(\mathrm{p}<$ 0.05). Overall, 44.63\% (54/121) dMMR tumors harbored KRAS mutation, however, dMMR tumors were less likely to have $N R A S$ mutation. Moreover, dMMR, KRAS and NRAS mutation were not prognostic factors for stage I III colorectal carcinoma.

Conclusions: This study confirms that the status of molecular markers involving mismatch repair status and $R A S$ mutation reflects the specific clinicopathological characteristics of colorectal carcinoma.

\section{INTRODUCTION}

Colorectal cancer (CRC) is the fourth most common cancer in China, with 331,300 new cases and 159,300 disease-related deaths in 2012 (Chen et al. 2016). The morbidity has increased steadily due to the growth of an aging population and the change of lifestyle in recent years, however, the exact mechanism and related predicted biomarkers are largely unknown.

During the past decades, microsatellite instability (MSI) and $R A S$ mutation have been well studied as two prevalent genetic biomarkers involved in colorectal carcinogenesis. The mismatch repair (MMR) system, which includes the proteins MLH1, MSH2, MSH6 and PMS2, can repair incorrect base-pairing or unmatched DNA loops to maintain genomic stability. MSI is caused by a deficient mismatch repair (dMMR) system, which leads to a high rate of mutations in repeat sequences and accounts for approximately $15 \%$ of all CRCs as well as virtually all Lynch syndrome (LS) patients (Geiersbach \& Samowitz 2011; Marra \& Boland 1995; Zhang et al. 2016). Tumors with high level microsatellite instability (MSI-H) caused by germ line mutations or epigenetic silencing of MMR genes have unique clinicopathological characteristics (Cunningham et al. 2010). In early stage CRC, patients with MSI-H demonstrated favorable 
55

prognosis compared to those with low level of microsatellite instability (MSI-L) and microsatellite stability (MSS) (Ribic et al. 2003; Sinicrope et al. 2011), however, these patients did not benefit from fluoropyrimidine-based adjuvant chemotherapy (Ribic et al. 2003; Sargent et al. 2010).

The $R A S$ gene family, the other significant biomarker, includes $K R A S, N R A S$ and $H R A S$, is located downstream in the epidermal growth factor receptor (EGFR) signal pathway. Mutations in the $R A S$ gene, which are thought to occur early in the adenoma-carcinoma continuum, activate the $R A S$ /MAPK pathway independently of EGFR activation, leading to poor response to EGFR inhibitors (Amado et al. 2008; Punt et al. 2016). Moreover, National Comprehensive Cancer Network (NCCN) clinical practice guidelines suggested that KRAS and NRAS gene mutations should be detected for metastatic CRC (mCRC) patients before treatment with Cetuximab and Panitumumab (Engstrom et al. 2009).

The status of dMMR and $R A S$ mutation has been widely studied in western countries. The frequency of dMMR CRCs ranged from 15-20\% (Giraldez et al. 2010; Sinicrope et al. 2011; Sinicrope et al. 2012), KRAS mutation ranged from 20-50\% (De Roock et al. 2010; Naguib et al. 2010; Palomba et al. 2016; Rosty et al. 2013; Sasaki et al. 2016) and NRAS mutation was noted in less than 5\% (De Roock et al. 2010; Palomba et al. 2016; Peeters et al. 2013; Russo et al. 2014). However, studies in China showed a lower frequency of dMMR compared with that in western populations, and the clinicopathological characteristics were also inconsistent (Huang et al. 2010; Jin et al. 2008; Ye et al. 2015). Although several studies reported the frequency of KRAS mutation in Chinese CRC patients, the number of samples was limited in most of these studies (Shen et al. 2011; Ye et al. 2015; Yunxia et al. 2010). Moreover, information about NRAS mutation in Chinese CRC patients was limited. Little has been studied on the association between status of dMMR and RAS mutation. Therefore, in the present study, we analyzed the dMMR and RAS mutation status of CRC patients to evaluate possible associations between dMMR, RAS mutation and the clinicopathological characteristics in primary colorectal carcinoma and we also attempted to explore the prognostic roles of dMMR and $R A S$ mutation. 
Materials and Methods

Eight hundred and thirteen formalin-fixed, paraffin-embedded tumor specimens from CRC patients who underwent primary surgical resection from 2013 to 2016 in the Affiliated Hospital of Qingdao University were selected for this study. The patients' selection method is presented in a consort diagram (Figure1). Patients who had undergone preoperative radiotherapy, chemotherapy and/or EGFR-targeted therapy were not included in this study.

The clinical and pathologic variables were extracted from medical records and pathological reports, which included age, gender, primary locations of tumor, tumor diameter, histological characteristics, TNM stage, smoking status, drinking status and family medication history. The patients were followed up until October 2017, and the data concerning cancer recurrence and patient survival were collected. Patients diagnosed with stage I - III colorectal carcinoma were used to explore the prognostic role of $\mathrm{dMMR}$ and $R A S$ mutation with disease-free survival (DFS) and overall survival (OS).

Primary locations of tumors were divided into the right side colon (from the cecum through the transverse colon), the left side colon (from the splenic flexure through the rectosigmoid flexure) and the rectum. Tumors were staged according to the criteria of the seventh edition of the American Joint Commission on Cancer (AJCC) TNM staging system. Mucinous adenocarcinoma and signet-ring cell carcinomas were recorded as mucin-producing tumors.

The study was approved by the Ethics Committee of the Affiliated Hospital of Qingdao University (No.20130049) and all patients had signed informed consent.

\section{Immunohistochemistry for MMR proteins}

As previously described (Lin et al. 2014b), all specimens were fixed in 10\% neutral buffered formalin and embedded in paraffin blocks. $3 \mu \mathrm{m}$-thick tissue sections were used for immunohistochemical analysis. Immunohistochemical staining was performed on an Automated Staining System (BenchMark XT, Ventana Medical Systems, Inc. Arizona, USA) according to the manufacturer's instructions. The ready-to-use antibodies were used as follows: MLH1 
109 (No.M1, Ventana Medical Systems Inc, Arizona, USA, working solution), PMS2 (No.EPR3947,

110 Ventana Medical Systems Inc, Arizona, USA, working solution), MSH2 (No.G219-1129,

111 Ventana Medical Systems Inc, Arizona, USA, working solution), MSH6 (No.44, Ventana

112 Medical Systems Inc, Arizona, USA, working solution).

113 The results were analyzed by two pathologists. Any tumor cell with nuclear staining was 114 recorded as positive staining. Intact expression for all these proteins was regarded as proficient

115 MMR (pMMR). Protein expression was defined as abnormal when nuclear staining of tumor 116 cells was absent in the presence of positive staining in stromal cells and lymphocytes (Figure2).

117 The standard criteria for diagnosis of dMMR was as follows: dMMR in MLH1: loss of MLH1 118 and PMS2; dMMR in MSH2: loss of MSH2 and MSH6; dMMR in MSH6: loss of MSH6; 119 dMMR in PMS2: loss of PMS2 (Richman et al. 2015).

\section{Analysis of $K R A S$ and $N R A S$ gene mutations by ARMS-PCR}

121 Formalin-fixed, paraffin-embedded tumor sections were deparaffinized and air dried, and DNA 122 was extracted using the Tiangen Blood and Tissue Kit (TiangenInc, Beijing, China). KRAS 123 (codons12 and 13) and NRAS (codons12, 13 and 61) mutations were detected by amplification 124 refractory mutation system in multiple quantitative polymerase chain reaction (ARMS-multi125 qPCR) analysis with the Human KRAS and NRAS Mutation Detection kit (YuanQi BioPharmaceutical Co., Ltd. Shanghai, China). The mutation points detected by this kit are listed in supplement 1. Codons of $R A S$ were amplified as described previously (Dong et al. 2016). Briefly, $3 \mu \mathrm{l}$ sample DNA was amplified in a $25 \mu \mathrm{l}$ reaction containing $9 \mu \mathrm{l}$ of Mix 1 and $13 \mu \mathrm{l}$ of PCRMix3. Positive and negative controls for each sample were run simultaneously. The program for the PCR amplification flanking KRAS mutation site was as follows: 1 cycle at $42{ }^{\circ} \mathrm{C}$ for 5 $131 \mathrm{~min} ; 1$ cycle at $94^{\circ} \mathrm{C}$ for $3 \mathrm{~min} ; 40$ cycles at $\left(94^{\circ} \mathrm{C}\right.$ for $15 \mathrm{sec} ; 60{ }^{\circ} \mathrm{C}$ for $\left.60 \mathrm{sec}\right)$. Fluorescence 132 signals were collected at $60^{\circ} \mathrm{C}$. The program for the PCR amplification flanking $N R A S$ mutation 133 site was as follows: 1 cycle at $42{ }^{\circ} \mathrm{C}$ for $5 \mathrm{~min} ; 1$ cycle at $94^{\circ} \mathrm{C}$ for $3 \mathrm{~min} ; 40$ cycles at $\left(94^{\circ} \mathrm{C}\right.$ for $13445 \mathrm{sec} ; 60{ }^{\circ} \mathrm{C}$ for $80 \mathrm{sec}$ ). Fluorescence signals were collected at $60{ }^{\circ} \mathrm{C}$. The mutations were 135 identified with a specific probe labeled with Hydroxy fluorescein (FAM). Amplicons were 
136

137

138

139

140

141

142

143

144

145

146

147

148

149

150

151

152

153

154

155

156

157

158

159

160

161

162

detected using ABI7500 Fast Real-Time PCR System (Thermo Fisher Scientific Inc, MA, US).

\section{Statistical analysis}

Results were analyzed with SPSS 19.0 (SPSS, Inc, Chicago). For comparison of the frequencies among groups, the Chi-square test and the Fisher exact test were used. Survival curves for DFS and OS were estimated using Kaplan-Meier analysis with the log-rank test. Probability (p) value $<0.05$ was considered as statistical significance.

\section{RESULTS}

\section{Patient characteristics}

The main characteristics of the patients are summarized in the Table 1 . There were $506(62.24 \%)$ males and $307(37.76 \%)$ females with a mean age of 64 years. The majority of the patients $(87.7 \%)$ were older than 50 years. $11.69 \%, 40.84 \%, 37.15 \%$ and $10.33 \%$ of patients presented with stage I, Stage II, stage III and stage IV disease, respectively. The primary location was more common in rectum (54.49\%). There were 283 (34.81\%) patients with a smoking history and 165 $(20.3 \%)$ patients with an alcohol in-taking history, respectively. There were $133(16.36 \%)$ patients with mucin-productive carcinoma.

\section{MMR status and associations with clinicopathological characteristics}

MMR status was successfully evaluated in 797 patients. 121 (15.18\%) patients exhibited dMMR. The rates of dMMR deficiency in MLH1, PMS2, MSH2 and MSH6 were 9.78\% (78/797), 1.25\% (10/797), 3.26\% (26/797) and $0.87 \%$ (7/797), respectively. The rates of deficiency in MLH1/PMS2 and MSH2/MSH6 were 11.92\% (88/797) and 4.14\% (33/797), respectively. The association of clinicopathological characteristics with MMR status is presented in Table 2. The proportion of dMMR was higher in patients $<50$ years old $(\mathrm{p}<0.001)$. A higher rate of dMMR was found in stage II cancers $(19.02 \%, \mathrm{p}=0.019)$. dMMR status was also associated with mucinous production $(\mathrm{p}<0.001)$, poor differentiation $(\mathrm{p}<0.001)$ and localization of the tumor to the right side of the colon $(\mathrm{p}<0.001)$. dMMR patients had a higher propensity to bowel wall invasion $(\mathrm{p}=0.018)$. 
Although dMMR tumors were present more often in patients with CRC family history, no significant difference $(22.92 \%$ vs $13.13 \%, \mathrm{p}>0.05)$ was found in this study. The loss of MSH2/MSH6 expression was more often observed in patients with CRC family history (12.5\% vs $3.58 \%, p=0.016)$. In other respects, the patients with tumors exhibiting dMMR were similar to those exhibiting pMMR.

\section{$R A S$ gene mutation and associations with clinicopathological characteristics}

$R A S$ status was tested from 813 patients. The mutation rates of $K R A S$ and $N R A S$ were $42.56 \%$ $(346 / 813)$ and $3.69 \%(30 / 813)$, respectively. There were three patients demonstrating mutation in both $K R A S$ and $N R A S$. Patients suffering from tumors with mucinous production had a higher incidence of $K R A S$ mutation compared with those having tumors without mucinous production $(54.89 \%$ vs $40.18 \%, \mathrm{p}=0.002)$. A higher rate of $K R A S$ mutation was found in stage II $(48.49 \%)$ compared with that in stage I, stage III and stage IV $(36.84 \%, 40.45 \%, 34.52 \%$, respectively) cancers $(\mathrm{p}=0.023)$ and in non-smokers compared with smokers $(46.6 \%$ vs34.98\%, $\mathrm{p}=0.001)$. Patients with CRC family history also showed higher rate of $K R A S$ mutation $(54.17 \%$ vs $37.39 \%$, $\mathrm{p}=0.013)$. Tumors with $R A S$ mutation showed lower propensity to lymph node metastasis $(\mathrm{p}=$ 0.006) and distant metastasis $(\mathrm{p}=0.048)$. No significant associations between $K R A S$ mutation and other clinicopathological characteristics were found in the present study. Meanwhile, NRAS mutation was not significantly associated with any clinicopathological characteristics (Table 3).

\section{Correlations between $R A S$ mutation and MMR status}

$R A S$ mutation rate was slightly higher in pMMR tumors than in $\mathrm{dMMR}$ tumors, but failed to reach a significant difference $(46.3 \%$ vs $44.63 \%, \mathrm{p}>0.05)$. There was also no obvious correlation between MMR status and KRAS mutation (42.3\% vs 44.63\%, p > 0.05). No NRAS mutation was detected in dMMR tumors. Compared with dMMR tumors, pMMR tumors had a higher propensity to harbor $N R A S$ mutation $(\mathrm{p}=0.009$, Table 4). The distribution of MMR and $K R A S$ status is shown in supplement 2. Correlation between $K R A S$ gene mutation and clinicopathological characteristics in dMMR tumors is summarized in Table 5. No significant association between $K R A S$ mutation and any clinicopathological characteristics were found in 
dMMR tumors.

\section{Prognostic value of $\mathrm{dMMR}$ and $\boldsymbol{R} A S$ mutation in stage I - III CRC}

Of the 813 followed-up patients, 729 patients were diagnosed with stage I - III CRC, including 95 stage I patients, 332 stage II patients and 302 stage III patients. dMMR and $R A S$ mutation were not prognostic for DFS and OS in stage I - III CRC (Figure.3). Of the $121 \mathrm{dMMR}$ patients, 109 patients were diagnosed with stage I - III CRC and 45.87\% (50/109) patients harbored KRAS mutation. However, $K R A S$ mutation was not prognostic factor for these patients (Figure 4).

\section{DISCUSSION}

As prognostic and predictive biomarkers, MMR deficiency and $R A S$ mutation are important for clinical treatment and prognosis of CRC patients. Compared with pMMR, patients with dMMR CRCs are reported to have unique clinicopathological characteristics such as poor differentiation, early stage, increased tumor-infiltrating lymphocytes and better clinical outcome (Brenner et al. 2014; Korphaisarn et al. 2015; Ribic et al. 2003). The $R A S$ gene is a predictive biomarker for the resistance to anti-EGFR monoclonal antibody (MoAb) treatment in mCRCs (Amado et al. 2008; Punt et al. 2016). However, geographic and racial differences between Chinese and other countries were reported (Huang et al. 2010; Ismael et al. 2017; Kim et al. 2007; Vasovcak et al. 2011; Ye et al. 2015), which need to be validated with large sample amounts. Furthermore, data regarding $R A S$ mutation frequency and $\mathrm{dMMR} \mathrm{CRC}$ is not consistent in China. Thus, we designed this study in the Chinese population aiming to explore the relationship between the $R A S$ mutation, MMR status and clinicopathological parameters, also expecting to find some prognostic and predictive biomarkers for CRC.

Our results demonstrated an overall MMR deficiency rate of $15.18 \%$, which is within the established range of 15-21\% (Giraldez et al. 2010; Sinicrope et al. 2012; Carethers et al. 2004;Cushman-Vokoun et al. 2013), but slightly higher than that reported from other Chinese populations (Huang et al. 2010; Jin et al. 2008; Ye et al. 2015). Reports from Korea (Jung et al. 2012) and Japan (Kadowaki et al. 2015) which used PCR-based MSI testing also showed that the 
217 frequencies of MSI-H CRCs were around 10\%. This discrepancy can be explained by the 218 different detective methods to some extent. Compared with PCR-based MSI testing examination, 219 immunohistochemistry is thought to be easily available and time-saving. Furthermore, 220 immunohistochemistry may detect MMR-deficient cases that can be potentially missed by PCR221 based MSI testing (Shia 2008).

222 Correlations between dMMR status and clinicopathological characteristics were 223 controversial (Ismael et al. 2017; Jin et al. 2008; Ribic et al. 2003; Sinicrope et al. 2011). Reports 224 from three independent Chinese groups (Huang et al. 2010; Jin et al. 2008; Ye et al. 2015)

225

226

227

228

229

230

231

232

233

234

235

236

237

238

239

240

241

242

243

indicated that $\mathrm{dMMR}$ had specific associations such as female gender, right sided colon tumors and mucious tumors. In a study including 1063 CRCs, Lin et al observed that MSI was associated not only with gender, tumor location and mucin production, but also with tumor differentiation and tumor stage (Lin et al. 2014a). In our current study, we found patients younger than 50 tended to be dMMR. These diverse findings may be attributed to different criteria for age division, ethnicities, environmental factors as well as the specificity and sensitivity of the detection methods.

In our study, there was a correlation between MSH2/MSH6 deficiency and family history of CRC, but not MLH1/PMS2 deficiency. In addition, according to the Bethesda criteria (Burt et al. 2010), 12 CRCs were diagnosed with LS. In MSH2/MSH6 deficient CRCs, 33.3\% (6/18) were LS, while in MLH1/PMS2 defective cases, 13.95\% (6/43) were LS, suggesting MSH2/MSH6 deficient patients had higher opportunity to be diagnosed with LS. Some of the recent studies may help to explain this finding: the majority dMMR CRCs were caused by inactivation of MLH1 and more than 70\% MLH1 deficiency was caused by $M L H 1$ promoter hypermethylation (Hampel et al. 2005), which could distinguish sporadic dMMR CRCs from LS cases, therefore, most MLH1 defective tumors were sporadic CRC. Another interesting phenomenon in our investigation is that we found most patients' family medical history was unclear and they did not know whether other family members had polyps removed, moreover, many cancers might be prevented by early stage colonoscopy, so the family history may be deceptive (Hampel 2014). 
244 Therefore, screening strategy based on family history may be improper. All patients with newly 245 diagnosed CRC should be screened for LS (Hampel 2014). Inconsistent with previous studies, 246 which indicated that patients with dMMR tumors had significantly better survival than that of 247 pMMR patients (Des Guetz et al. 2009; Korphaisarn et al. 2015; Lanza et al. 2006), our study 248 showed that dMMR was not a prognostic factor for patients with stage I - III CRC, although the 249 incidence of dMMR in stage III disease was lower, suggesting that dMMR tumors had lower 250 propensity to metastasize.

In the present study, the mutation rates of $K R A S$ and $N R A S$ are $42.56 \%$ and $3.69 \%$, 252 respectively. The $K R A S$ mutation rate is significantly higher than the value of $20.7 \%$ among 314 CRC patients from Taiwan, China (Liou et al. 2011), 22\% among 202 CRC patients from the England (Naguib et al. 2010), 30.1\% among 392 CRC patients from Switzerland (Zlobec et al. 2010), but similar to that previously reported in Guangzhou, China (43.9\%, 25/57) (Mao et al. 2012). Several factors may lead to such differences, such as sample size, dietary and lifestyle factors, as well as racial and/or environmental differences. Furthermore, we detected the coding sequence of codon 12 and codon 13 in exon 2 of the $K R A S$ gene, which may help to explain the higher percentage of $K R A S$ mutation than those detected in codon12 only. Except for exon 2, recent studies have shown $5-10 \%$ of tumors harbored exon 3 or exon 4 mutation (Janakiraman et al. 2010; Lin et al. 2014a), which would also result in resistance to anti-EGFR inhibitors. Therefore, extending the detection spectrum of $R A S$ might help to optimize the selection of the CRC patients to receive anti-EGFR MoAbs.

The frequency of $K R A S$ mutation has been reported to be associated with age, gender, differentiation and tumor stage (Gao et al. 2012; Li et al. 2011; Ye et al. 2015; Yunxia et al. 2010; Zhu et al. 2012). Inconsistent with these results, our study showed that KRAS mutation was associated with mucin production, tumor stage, non-smoking and CRC family history. $R A S$ mutated tumors showed lower propensity to lymph node and distant metastasis. No convincing evidence demonstrates that KRAS mutation is an independent prognostic factor for CRC (Jin et al. 2008; Palomba et al. 2016; Russo et al. 2014; Yunxia et al. 2010). In the present study, no 
271

272

273

274

275

276

277

278

279

280

281

282

283

284

285

286

287

288

289

290

291

292

293

294

295

296

297

associations of KRAS mutation with DFS and OS were found in patients with stage I - III CRC. Further studies based on longer follow-up time and larger sample size are needed to confirm this conclusion.

In our study, the percentage of the four tumor subgroups, including $\mathrm{dMMR} / K R A S$ mutation, $\mathrm{dMMR} / K R A S$ wild-type, $\mathrm{pMMR} / K R A S$ mutation and $\mathrm{pMMR} / K R A S$ wild-type tumors was $6.78 \%$, $8.4 \%, 35.88 \%, 48.94 \%$, respectively, which is similar to the data reported by a study from Beijing, China (Ye et al. 2015). According to recent reports (Nash et al. 2009; Roth et al. 2010), patients with a MSS/KRAS mutant tumor had the worst survival than the other three groups. Therefore, dMMR and $K R A S$ markers may provide a foundation for developing a molecular prognostic scoring system for CRC patients in the future.

Previous studies have shown that pMMR patients tended to harbor more KRAS mutation than dMMR patients (Naguib et al. 2010; Ye et al. 2015). One hypothesis for this result is that $B R A F$ and $K R A S$ mutations were almost mutually exclusive in CRC and MSI tumors are more likely to harbor a $B R A F$ mutation, so MSS tumors might harbor more $K R A S$ mutations (Naguib et al. 2010). However, in the present study, we did not find any differences in $K R A S$ mutation between pMMR and dMMR tumors, and further studies based on larger sample size are needed to explore this controversy in Chinese CRCs.

Additionally, our study provided an opportunity to investigate the status of $K R A S$ mutation in Chinese dMMR patients. KRAS mutation presented in $44.63 \%$ dMMR patients in our study, similar to previous studies in western countries (Cushman-Vokoun et al. 2013; Oliveira 2004). All of these results indicate that $K R A S$ mutation could be quite common in dMMR tumors. There were no associations between $K R A S$ mutation and clinicopathologic characteristics in dMMR tumors. A study conducted by Nash et al indicated that $K R A S$ status was an independent prognostic factor in early stage MSI CRC patients (Nash et al. 2009). Moreover, MSI patients with wild-type $K R A S$ and $B R A F$ tumors have more favorable prognosis than patients with mutated KRAS or BRAF tumors in early stage CRC (de Cuba et al. 2016; Phipps et al. 2015). However, we did not find $K R A S$ mutation as a prognostic factor for dMMR patients with stage I - 
III CRC.

$N R A S$, as one of the $R A S$ family, showed close relations with $K R A S$. Unlike $K R A S, N R A S$ mutation was rarely detected in CRC patients. In our study, the mutation rate of $N R A S$ was 3.69\%, similar to previous reports (Chang et al. 2016; Irahara et al. 2010; Palomba et al. 2016; Peeters et al. 2013). Moreover, we observed 25/388 KRAS wild-type tumors with NRAS mutation, which can partially help to explain the resistance to anti-EGFR MoAb in some $K R A S$ wild-type patients. Considering the heavy financial burden in MoAb treatment in CRC patients, NRAS mutation should be tested before MoAb treatment in $K R A S$ wild-type tumors. Another interesting phenomenon is that no $N R A S$ mutation was detected in dMMR patients, which suggested $N R A S$ mutation might be mutually exclusive with dMMR. Meanwhile, NRAS mutation was not significantly associated with any clinicopathologic characteristics in our study.

However, our results should be elucidated with consideration of its limitations: first, the sample size was relatively small, rendering some findings inconclusive; second, we used commercially available kit authenticated by China Food and Drug Administration (CFDA) and the mutation subgroups were uncertain. A study conducted by Lin et al, demonstrated that mutation in $K R A S$ codon 12 was associated with significantly poorer outcome than mutations elsewhere or wild-type $K R A S$ (Lin et al. 2014a). Therefore, the subgroup of mutation codons should be carefully explored in future; third, we did not collect data of clinical management, therefore, the influence of clinical treatment for survival was uncertain.

\section{Conclusion}

In conclusion, this was an exploratory analysis of correlations between $R A S$ mutation and MMR status with clinicopathological characteristics in Eastern Chinese CRC patients. The status of these molecular markers, involving MLH1/PMS2, MSH2/MSH6, KRAS and NRAS mutation, reflects the specific clinicopathological characteristics of CRC. More comprehensive molecular classification and survival analysis should be explored in future experiments. 
325

326

327

328

329

330

331

332

333

334

335

336

337

338

339

340

341

342

343

344

345

346

347

348

349

350

351

\section{Acknowledgement}

None

\section{References}

Amado RG, Wolf M, Peeters M, Van Cutsem E, Siena S, Freeman DJ, Juan T, Sikorski R, Suggs S, Radinsky R, Patterson SD, and Chang DD. 2008. Wild-type KRAS is required for panitumumab efficacy in patients with metastatic colorectal cancer. J Clin Oncol 26:1626-1634. 10.1200/JCO.2007.14.7116

Brenner H, Kloor M, and Pox CP. 2014. Colorectal cancer. Lancet 383:1490-1502. 10.1016/s0140-6736(13)61649-9

Burt RW, Barthel JS, Dunn KB, David DS, Drelichman E, Ford JM, Giardiello FM, Gruber SB, Halverson AL, Hamilton SR, Ismail MK, Jasperson K, Lazenby AJ, Lynch PM, Martin EW, Jr., Mayer RJ, Ness RM, Provenzale D, Rao MS, Shike M, Steinbach G, Terdiman JP, and Weinberg D. 2010. NCCN clinical practice guidelines in oncology. Colorectal cancer screening. J Natl Compr Canc Netw 8:8-61.

Carethers JM, Smith EJ, Behling CA, Nguyen L, Tajima A, Doctolero RT, Cabrera BL, Goel A, Arnold CA, Miyai K, and Boland CR. 2004. Use of 5-fluorouracil and survival in patients with microsatellite-unstable colorectal cancer. Gastroenterology 126:394-401. 10.1053/j.gastro.2003.12.023

Chang YY, Lin PC, Lin HH, Lin JK, Chen WS, Jiang JK, Yang SH, Liang WY, and Chang SC. 2016. Mutation spectra of RAS gene family in colorectal cancer. Am J Surg 212:537544.e533. 10.1016/j.amjsurg.2016.02.013

Chen W, Zheng R, Zuo T, Zeng H, Zhang S, and He J. 2016. National cancer incidence and mortality in China, 2012. Chin J Cancer Res 28:1-11. 10.3978/j.issn.10009604.2016.02.08

Cunningham D, Atkin W, Lenz H-J, Lynch HT, Minsky B, Nordlinger B, and Starling N. 2010. Colorectal cancer. Lancet 375:1030-1047. 
352

353

354

355

356

357

358

359

360

361

362

363

364

365

366

367

368

369

370

371

372

373

374

375

376

377

378

Cushman-Vokoun AM, Stover DG, Zhao Z, Koehler EA, Berlin JD, and Vnencak-Jones CL. 2013. Clinical utility of KRAS and BRAF mutations in a cohort of patients with colorectal neoplasms submitted for microsatellite instability testing. Clin Colorectal Cancer 12:168-178. 10.1016/j.clcc.2013.04.005

de Cuba EMV, Snaebjornsson P, Heideman DAM, van Grieken NCT, Bosch LJW, Fijneman RJA, Belt E, Bril H, Stockmann HBAC, Hooijberg E, Punt CJA, Koopman M, Nagtegaal ID, Coupé VHM, Carvalho B, and Meijer GA. 2016. Prognostic value ofBRAFandKRASmutation status in stage II and III microsatellite instable colon cancers. Int J Cancer 138:1139-1145. 10.1002/ijc.29855

De Roock W, Claes B, Bernasconi D, De Schutter J, Biesmans B, Fountzilas G, Kalogeras KT, Kotoula V, Papamichael D, Laurent-Puig P, Penault-Llorca F, Rougier P, Vincenzi B, Santini D, Tonini G, Cappuzzo F, Frattini M, Molinari F, Saletti P, De Dosso S, Martini M, Bardelli A, Siena S, Sartore-Bianchi A, Tabernero J, Macarulla T, Di Fiore F, Gangloff AO, Ciardiello F, Pfeiffer P, Qvortrup C, Hansen TP, Van Cutsem E, Piessevaux H, Lambrechts D, Delorenzi M, and Tejpar S. 2010. Effects of KRAS, BRAF, NRAS, and PIK3CA mutations on the efficacy of cetuximab plus chemotherapy in chemotherapy-refractory metastatic colorectal cancer: a retrospective consortium analysis. Lancet Oncol 11:753-762. 10.1016/s1470-2045(10)70130-3

Des Guetz G, Schischmanoff O, Nicolas P, Perret G-Y, Morere J-F, and Uzzan B. 2009. Does microsatellite instability predict the efficacy of adjuvant chemotherapy in colorectal cancer? A systematic review with meta-analysis. Eur J Cancer 45:1890-1896. 10.1016/j.ejca.2009.04.018

Dong YU, Ren W, Qi J, Jin BO, Li Y, Tao H, Xu R, Li Y, Zhang Q, and Han B. 2016. EGFR, ALK, RET, KRAS and BRAF alterations in never-smokers with non-small cell lung cancer. Oncol Lett 11:2371-2378. 10.3892/o1.2016.4235

Engstrom aF, Arnoletti JP, III ABB, Chen Y-J, Choti MA, Cooper HS, Covey A, Dilawari RA, Early DS, Enzinge PC, Fakih MG, Fleshman J, Fuchs C, Grem JL, Kiel K, Knol JA, 
Leong LA, Lin E, Mulcahy MF, Rao S, Ryan DP, Saltz L, Shibata D, Skibber JM, Sofocleous C, Thomas J, Venook AP, and Willett C. 2009. The NCCN Colon Cancer Clinical Practice Guidelines in Oncology. J Natl Compr Canc Netw 7:778-831.

Gao J, Sun ZW, Li YY, and Shen L. 2012. [Mutations of KRAS and BRAF in Chinese patients with colorectal carcinoma: analyses of 966 cases]. Zhonghua Bing Li Xue Za Zhi 41:579583. 10.3760/cma.j.issn.0529-5807.2012.09.002

Geiersbach KB, and Samowitz WS. 2011. Microsatellite instability and colorectal cancer. Arch Pathol Lab Med 135:1269-1277. 10.5858/arpa.2011-0035-RA

Giraldez MD, Balaguer F, Bujanda L, Cuatrecasas M, Munoz J, Alonso-Espinaco V, Larzabal M, Petit A, Gonzalo V, Ocana T, Moreira L, Enriquez-Navascues JM, Boland CR, Goel A, Castells A, and Castellvi-Bel S. 2010. MSH6 and MUTYH deficiency is a frequent event in early-onset colorectal cancer. Clin Cancer Res 16:5402-5413. 10.1158/10780432.CCR-10-1491

Hampel H. 2014. NCCN increases the emphasis on genetic/familial high-risk assessment in colorectal cancer. J Natl Compr Canc Netw 12:829-831.

Hampel H, Frankel WL, Martin E, Arnold M, Khanduja K, Kuebler P, Nakagawa H, Sotamaa K, Prior TW, Westman J, Panescu J, Fix D, Lockman J, Comeras I, and de la Chapelle A. 2005. Screening for the Lynch syndrome (hereditary nonpolyposis colorectal cancer). $N$ Engl J Med 352:1851-1860. 10.1056/NEJMoa043146

Huang YQ, Yuan Y, Ge WT, Hu HG, Zhang SZ, and Zheng S. 2010. Comparative features of colorectal and gastric cancers with microsatellite instability in Chinese patients. $J$ Zhejiang Univ Sci B 11:647-653. 10.1631/jzus.B1000198

Irahara N, Baba Y, Nosho K, Shima K, Yan L, Dias-Santagata D, Iafrate AJ, Fuchs CS, Haigis KM, and Ogino S. 2010. NRAS mutations are rare in colorectal cancer. Diagn Mol Pathol 19:157-163. 10.1097/PDM.0b013e3181c93fd1

Ismael NEHS, El Sheikh SA, Talaat SM, and Salem EM. 2017. Mismatch Repair Proteins and Microsatellite Instability in Colorectal Carcinoma (MLH1, MSH2, MSH6 and PMS2): 
406

407

408

409

410

411

412

413

414

415

416

417

418

419

420

421

422

423

424

425

426

427

Histopathological and Immunohistochemical Study. Open Access Maced J Med Sci 5:9. 10.3889/oamjms.2017.003

Janakiraman M, Vakiani E, Zeng Z, Pratilas CA, Taylor BS, Chitale D, Halilovic E, Wilson M, Huberman K, Ricarte Filho JC, Persaud Y, Levine DA, Fagin JA, Jhanwar SC, Mariadason JM, Lash A, Ladanyi M, Saltz LB, Heguy A, Paty PB, and Solit DB. 2010. Genomic and Biological Characterization of Exon 4 KRAS Mutations in Human Cancer. Cancer Res 70:5901-5911. 10.1158/0008-5472.can-10-0192

Jin HY, Liu X, Li VK, Ding Y, Yang B, Geng J, Lai R, Ding S, Ni M, and Zhao R. 2008. Detection of mismatch repair gene germline mutation carrier among Chinese population with colorectal cancer. BMC Cancer 8:44. 10.1186/1471-2407-8-44

Jung SB, Lee HI, Oh HK, Shin IH, and Jeon CH. 2012. Clinico-pathologic Parameters for Prediction of Microsatellite Instability in Colorectal Cancer. Cancer Res Treat 44:179186. $10.4143 / \mathrm{crt} .2012 .44 .3 .179$

Kadowaki S, Kakuta M, Takahashi S, Takahashi A, Arai Y, Nishimura Y, Yatsuoka T, Ooki A, Yamaguchi K, Matsuo K, Muro K, and Akagi K. 2015. Prognostic value of KRAS and BRAF mutations in curatively resected colorectal cancer. World $J$ Gastroenterol 21:1275-1283. 10.3748/wjg.v21.i4.1275

Kim GP, Colangelo LH, Wieand HS, Paik S, Kirsch IR, Wolmark N, Allegra CJ, and National Cancer I. 2007. Prognostic and predictive roles of high-degree microsatellite instability in colon cancer: a National Cancer Institute-National Surgical Adjuvant Breast and Bowel Project Collaborative Study. J Clin Oncol 25:767-772. 10.1200/JCO.2006.05.8172

Korphaisarn K, Pongpaibul A, Limwongse C, Roothumnong E, Klaisuban W, Nimmannit A, Jinawath A, and Akewanlop C. 2015. Deficient DNA mismatch repair is associated with favorable prognosis in Thai patients with sporadic colorectal cancer. World $J$ Gastroenterol 21:926-934. 10.3748/wjg.v21.i3.926

Lanza G, Gafa R, Santini A, Maestri I, Guerzoni L, and Cavazzini L. 2006. Immunohistochemical Test for MLH1 and MSH2 Expression Predicts Clinical Outcome 
433

434

435

436

437

438

439

440

441

442

443

444

445

446

447

448

449

450

451

452

453

454

455

456

457

458

459

in Stage II and III Colorectal Cancer Patients. J Clin Oncol 24:2359-2367. $10.1200 /$ jco.2005.03.2433

Li HT, Lu YY, An YX, Wang X, and Zhao QC. 2011. KRAS, BRAF and PIK3CA mutations in human colorectal cancer: relationship with metastatic colorectal cancer. Oncol Rep 25:1691-1697. 10.3892/or.2011.1217

Lin C-C, Lin J-K, Lin T-C, Chen W-S, Yang S-H, Wang H-S, Lan Y-T, Jiang J-K, Yang M-H, and Chang S-C. 2014a. The prognostic role of microsatellite instability, codonspecificKRAS, andBRAFmutations in colon cancer. J Surg Onco 110:451-457. $10.1002 /$ jso. 23675

Lin S, YuJun L, XiaoMing X, and WenWen R. 2014b. Expression and significance of leptin receptor, p-STAT3 and p-AKT in diffuse large B-cell lymphoma. Acta Histochem 116:126-130. 10.1016/j.acthis.2013.06.003

Liou JM, Wu MS, Shun CT, Chiu HM, Chen MJ, Chen CC, Wang HP, Lin JT, and Liang JT. 2011. Mutations in BRAF correlate with poor survival of colorectal cancers in Chinese population. Int J Colorectal Dis 26:1387-1395. 10.1007/s00384-011-1229-1

Mao C, Zhou J, Yang Z, Huang Y, Wu X, Shen H, Tang J, and Chen Q. 2012. KRAS , BRAF and PIK3CA Mutations and the Loss of PTEN Expression in Chinese Patients with Colorectal Cancer. PLoS One 7:e36653. 10.1371/journal.pone.0036653.t001

Marra G, and Boland CR. 1995. Hereditary nonpolyposis colorectal cancer: the syndrome, the genes, and historical perspectives. J Natl Cancer Inst 87:1114-1125.

Naguib A, Mitrou PN, Gay LJ, Cooke JC, Luben RN, Ball RY, McTaggart A, Arends MJ, and Rodwell SA. 2010. Dietary, lifestyle and clinicopathological factors associated with BRAF and K-ras mutations arising in distinct subsets of colorectal cancers in the EPIC Norfolk study. BMC Cancer 10:99. 10.1186/1471-2407-10-99

Nash GM, Gimbel M, Cohen AM, Zeng Z-S, Ndubuisi MI, Nathanson DR, Ott J, Barany F, and Paty PB. 2009. KRAS Mutation and Microsatellite Instability: Two Genetic Markers of Early Tumor Development That Influence the Prognosis of Colorectal Cancer. Ann Surg 
Oncol 17:416-424. 10.1245/s10434-009-0713-0

Oliveira C. 2004. Distinct patterns of KRAS mutations in colorectal carcinomas according to germline mismatch repair defects and hMLH1 methylation status. Hum Mol Genet 13:2303-2311. 10.1093/hmg/ddh238

Palomba G, Doneddu V, Cossu A, Paliogiannis P, Manca A, Casula M, Colombino M, Lanzillo A, Defraia E, Pazzola A, Sanna G, Putzu C, Ortu S, Scartozzi M, Ionta MT, Baldino G, Sarobba G, Capelli F, Sedda T, Virdis L, Barca M, Gramignano G, Budroni M, Tanda F, and Palmieri G. 2016. Prognostic impact of KRAS, NRAS, BRAF, and PIK3CA mutations in primary colorectal carcinomas: a population-based study. $J$ Transl Med 14. $10.1186 / \mathrm{s} 12967-016-1053-\mathrm{z}$

Peeters M, Oliner KS, Parker A, Siena S, Van Cutsem E, Huang J, Humblet Y, Van Laethem JL, Andre T, Wiezorek J, Reese D, and Patterson SD. 2013. Massively parallel tumor multigene sequencing to evaluate response to panitumumab in a randomized phase III study of metastatic colorectal cancer. Clin Cancer Res 19:1902-1912. 10.1158/10780432.CCR-12-1913

Phipps AI, Limburg PJ, Baron JA, Burnett-Hartman AN, Weisenberger DJ, Laird PW, Sinicrope FA, Rosty C, Buchanan DD, Potter JD, and Newcomb PA. 2015. Association Between Molecular Subtypes of Colorectal Cancer and Patient Survival. Gastroenterology 148:7787.e72. 10.1053/j.gastro.2014.09.038

Punt CJA, Koopman M, and Vermeulen L. 2016. From tumour heterogeneity to advances in precision treatment of colorectal cancer. Nat Rev Clin Oncol 14:235-246. 10.1038/nrclinonc.2016.171

Ribic CM, Sargent DJ, Moore MJ, Thibodeau SN, French AJ, Goldberg RM, Hamilton SR, Laurent-Puig P, Gryfe R, Shepherd LE, Tu D, Redston M, and Gallinger S. 2003. Tumor microsatellite-instability status as a predictor of benefit from fluorouracil-based adjuvant chemotherapy for colon cancer. $N$ Engl J Med 349:247-257. 10.1056/NEJMoa022289

Richman S.2015. Deficient mismatch repair: Read all about it (Review). Int J Oncol 47: 1189- 
1202. 10.3892/ijo.2015.3119Rosty C, Young JP, Walsh MD, Clendenning M, Walters RJ, Pearson S, Pavluk E, Nagler B, Pakenas D, Jass JR, Jenkins MA, Win AK, Southey MC, Parry S, Hopper JL, Giles GG, Williamson E, English DR, and Buchanan DD. 2013. Colorectal carcinomas with KRAS mutation are associated with distinctive morphological and molecular features. Mod Pathol 26:825-834. 10.1038/modpathol.2012.240

Roth AD, Tejpar S, Delorenzi M, Yan P, Fiocca R, Klingbiel D, Dietrich D, Biesmans B, Bodoky G, Barone C, Aranda E, Nordlinger B, Cisar L, Labianca R, Cunningham D, Van Cutsem E, and Bosman F. 2010. Prognostic role of KRAS and BRAF in stage II and III resected colon cancer: results of the translational study on the PETACC-3, EORTC 40993, SAKK 60-00 trial. J Clin Oncol 28:466-474. 10.1200/JCO.2009.23.3452

Russo AL, Borger DR, Szymonifka J, Ryan DP, Wo JY, Blaszkowsky LS, Kwak EL, Allen JN, Wadlow RC, Zhu AX, Murphy JE, Faris JE, Dias-Santagata D, Haigis KM, Ellisen LW, Iafrate AJ, and Hong TS. 2014. Mutational analysis and clinical correlation of metastatic colorectal cancer. Cancer 120:1482-1490. 10.1002/cncr.28599

Sargent DJ, Marsoni S, Monges G, Thibodeau SN, Labianca R, Hamilton SR, French AJ, Kabat B, Foster NR, Torri V, Ribic C, Grothey A, Moore M, Zaniboni A, Seitz JF, Sinicrope F, and Gallinger S. 2010. Defective mismatch repair as a predictive marker for lack of efficacy of fluorouracil-based adjuvant therapy in colon cancer. J Clin Oncol 28:32193226. $10.1200 / J C O .2009 .27 .1825$

Sasaki Y, Akasu T, Saito N, Kojima H, Matsuda K, Nakamori S, Komori K, Amagai K, Yamaguchi T, Ohue M, Nagashima K, and Yamada Y. 2016. Prognostic and predictive value of extendedRASmutation and mismatch repair status in stage III colorectal cancer. Cancer Sci 107:1006-1012. 10.1111/cas.12950

Shen H, Yuan Y, Hu HG, Zhong X, Ye XX, Li MD, Fang WJ, and Zheng S. 2011. Clinical significance of K-ras and BRAF mutations in Chinese colorectal cancer patients. World $J$ Gastroenterol 17:809-816. 10.3748/wjg.v17.i6.809 
514

515

516

517

518

519

520

521

522

523

524

525

526

527

528

529

530

531

532

533

534

535

536

537

538

539

540

Shia J. 2008. Immunohistochemistry versus microsatellite instability testing for screening colorectal cancer patients at risk for hereditary nonpolyposis colorectal cancer syndrome. Part I. The utility of immunohistochemistry. $J$ Mol Diagn 10:293-300. 10.2353/jmoldx.2008.080031

Sinicrope FA, Foster NR, Thibodeau SN, Marsoni S, Monges G, Labianca R, Kim GP, Yothers G, Allegra C, Moore MJ, Gallinger S, and Sargent DJ. 2011. DNA mismatch repair status and colon cancer recurrence and survival in clinical trials of 5-fluorouracil-based adjuvant therapy. J Natl Cancer Inst 103:863-875. 10.1093/jnci/djr153

Sinicrope FA, Foster NR, Yoon HH, Smyrk TC, Kim GP, Allegra CJ, Yothers G, Nikcevich DA, and Sargent DJ. 2012. Association of obesity with DNA mismatch repair status and clinical outcome in patients with stage II or III colon carcinoma participating in NCCTG and NSABP adjuvant chemotherapy trials. $J$ Clin Oncol 30:406-412. 10.1200/JCO.2011.39.2563

Vasovcak P, Pavlikova K, Sedlacek Z, Skapa P, Kouda M, Hoch J, and Krepelova A. 2011. Molecular genetic analysis of 103 sporadic colorectal tumours in Czech patients. PLoS One 6:e24114. 10.1371/journal.pone.0024114

Ye JX, Liu Y, Qin Y, Zhong HH, Yi WN, and Shi XY. 2015. KRAS and BRAF gene mutations and DNA mismatch repair status in Chinese colorectal carcinoma patients. World $J$ Gastroenterol 21:1595-1605. 10.3748/wjg.v21.i5.1595

Yunxia Z, Jun C, Guanshan Z, Yachao L, Xueke Z, and Jin L. 2010. Mutations in epidermal growth factor receptor and K-ras in Chinese patients with colorectal cancer. BMC Med Genet 11:34. 10.1186/1471-2350-11-34

Zhang C-M, Lv J-F, Gong L, Yu L-Y, Chen X-P, Zhou H-H, and Fan L. 2016. Role of Deficient Mismatch Repair in the Personalized Management of Colorectal Cancer. Inter J Env Res Pub Heal 13:892. 10.3390/ijerph13090892

Zhu XL, Cai X, Zhang L, Yang F, Sheng WQ, Lu YM, Du X, and Zhou XY. 2012. [KRAS and BRAF gene mutations in correlation with clinicopathologic features of colorectal 
541 carcinoma in Chinese]. Zhonghua Bing Li Xue Za Zhi 41:584-589. $542 \quad$ 10.3760/cma.j.issn.0529-5807.2012.09.003

543 Zlobec I, Bihl MP, Schwarb H, Terracciano L, and Lugli A. 2010. Clinicopathological and 544 protein characterization of BRAF- and K-RAS-mutated colorectal cancer and 545 implications for prognosis. Int J Cancer 127:367-380. 10.1002/ijc.25042 


\section{Table 1 (on next page)}

Clinicopathological information of the studied patients $(n=813)$. 


\begin{tabular}{|c|c|c|}
\hline Characteristics & Number & $(\%)$ \\
\hline \multicolumn{3}{|l|}{ Gender } \\
\hline Male & 506 & 62.24 \\
\hline Female & 307 & 37.76 \\
\hline \multicolumn{3}{|l|}{ Age } \\
\hline$<50$ & 100 & 12.3 \\
\hline$\geq 50$ & 713 & 87.7 \\
\hline \multicolumn{3}{|l|}{ Location } \\
\hline Right side colon & 181 & 22.26 \\
\hline Left side colon & 189 & 23.25 \\
\hline Rectum & 443 & 54.49 \\
\hline \multicolumn{3}{|l|}{ Mucin production } \\
\hline With & 133 & 16.36 \\
\hline Without & 680 & 83.64 \\
\hline \multicolumn{3}{|c|}{ Tumor differentiation } \\
\hline Poor & 138 & 16.97 \\
\hline moderate & 599 & 73.68 \\
\hline Well & 33 & 4.06 \\
\hline Unknown & 43 & 5.29 \\
\hline \multicolumn{3}{|l|}{ Tumor stage } \\
\hline I & 95 & 11.69 \\
\hline II & 332 & 40.84 \\
\hline III & 302 & 37.15 \\
\hline IV & 84 & 10.33 \\
\hline \multicolumn{3}{|c|}{ Bowel wall invasion (T) } \\
\hline $\mathrm{T} 1$ & 21 & 2.58 \\
\hline $\mathrm{T} 2$ & 104 & 12.79 \\
\hline
\end{tabular}




\begin{tabular}{|c|c|c|}
\hline $\mathrm{T} 3$ & 336 & 41.33 \\
\hline $\mathrm{T} 4$ & 352 & 43.3 \\
\hline \multicolumn{3}{|c|}{ Lymph node metastasis (N) } \\
\hline N0 & 458 & 56.33 \\
\hline N1 & 203 & 24.97 \\
\hline N2 & 152 & 18.7 \\
\hline \multicolumn{3}{|c|}{ Distant metastasis (M) } \\
\hline M0 & 729 & 89.67 \\
\hline M1 & 84 & 10.33 \\
\hline \multicolumn{3}{|c|}{ Lymphovascular invasion } \\
\hline Yes & 339 & 41.7 \\
\hline No & 462 & 56.83 \\
\hline Unknown & 12 & 1.47 \\
\hline \multicolumn{3}{|c|}{ Alcohol intake } \\
\hline Ever & 165 & 20.3 \\
\hline Never & 648 & 79.7 \\
\hline \multicolumn{3}{|l|}{ Smoking } \\
\hline Ever & 283 & 34.81 \\
\hline Never & 530 & 65.19 \\
\hline \multicolumn{3}{|c|}{ Colorectal family history } \\
\hline Yes & 48 & 5.9 \\
\hline No & 337 & 41.45 \\
\hline Unknown & 428 & 52.65 \\
\hline
\end{tabular}

1 


\section{Table 2 (on next page)}

Correlations between mismatch repair protein deficiency and clinicopathological characteristics $(n=797)$. 


\begin{tabular}{|c|c|c|c|c|c|c|c|}
\hline \multirow{2}{*}{ Characteristics } & \multirow{2}{*}{ Number } & \multicolumn{2}{|c|}{ dMMR } & \multicolumn{2}{|c|}{ MLH1/ PMS2 } & \multicolumn{2}{|c|}{ MSH2/MSH6 } \\
\hline & & Defective (\%) & $P$ value & Defective (\%) & $P$ value & Defective (\%) & $P$ value \\
\hline \multicolumn{8}{|l|}{ Gender } \\
\hline Male & 495 & $73(14.75)$ & 0.662 & $52(10.51)$ & 0.561 & $21(4.24)$ & 0.853 \\
\hline Female & 302 & $48(15.89)$ & & $36(11.92)$ & & $12(3.97)$ & \\
\hline \multicolumn{8}{|l|}{ Age } \\
\hline$<50$ & 99 & $29(29.29)$ & $<0.001$ & $23(23.23)$ & $<0.001$ & $6(6.06)$ & $0.284^{*}$ \\
\hline$\geq 50$ & 698 & $92(13.18)$ & & $65(9.31)$ & & $27(3.87)$ & \\
\hline \multicolumn{8}{|l|}{ Location } \\
\hline Right side colon & 173 & $61(35.26)$ & $<0.001$ & $43(24.86)$ & $<0.001$ & $18(10.4)$ & $<0.001$ \\
\hline Left side colon & 185 & $25(13.51)$ & & $18(9.73)$ & & $7(3.78)$ & \\
\hline Rectum & 439 & 35 (7.97) & & $27(6.15)$ & & $8(1.82)$ & \\
\hline \multicolumn{8}{|l|}{ Mucin production } \\
\hline With & 131 & $36(27.48)$ & $<0.001$ & $25(19.08)$ & $<0.001$ & $11(8.4)$ & 0.007 \\
\hline Without & 666 & $85(12.76)$ & & $63(9.46)$ & & $22(3.3)$ & \\
\hline \multicolumn{8}{|c|}{ Tumor differentiation } \\
\hline Poor & 134 & $36(26.87)$ & $<0.001$ & $24(17.91)$ & $<0.001$ & $12(8.96)$ & $0.012^{*}$ \\
\hline moderate & 589 & $71(12.05)$ & & $51(8.66)$ & & $20(3.39)$ & \\
\hline Well & 31 & $4(12.9)$ & & $3(9.68)$ & & $1(3.23)$ & \\
\hline Unknown & 43 & & & & & & \\
\hline \multicolumn{8}{|l|}{ Tumor stage } \\
\hline I & 94 & $6(6.38)$ & 0.019 & $5(5.32)$ & 0.110 & $1(1.06)$ & $0.288^{*}$ \\
\hline II & 326 & $62(19.02)$ & & $45(13.81)$ & & $17(5.21)$ & \\
\hline III & 301 & $41(13.62)$ & & $30(9.97)$ & & $11(3.65)$ & \\
\hline IV & 76 & $12(15.79)$ & & $8(10.52)$ & & $4(5.26)$ & \\
\hline \multicolumn{8}{|c|}{ Bowel wall invasion (T) } \\
\hline $\mathrm{T} 1$ & 20 & $3(15)$ & 0.018 & $2(10)$ & 0.139 & $1(5)$ & $0.067^{*}$ \\
\hline
\end{tabular}




\begin{tabular}{|c|c|c|c|c|c|c|c|}
\hline $\mathrm{T} 2$ & 102 & $5(4.9)$ & & $5(4.9)$ & & $0(0)$ & \\
\hline T3 & 334 & $59(17.66)$ & & $44(13.17)$ & & $15(4.49)$ & \\
\hline $\mathrm{T} 4$ & 341 & $54(15.83)$ & & $37(10.85)$ & & $17(4.98)$ & \\
\hline \multicolumn{8}{|c|}{ Lymph node metastasis $(\mathrm{N})$} \\
\hline N0 & 445 & $74(16.63)$ & 0.192 & $54(12.13)$ & 0.354 & $20(4.49)$ & 0.583 \\
\hline N1 & 200 & $31(15.5)$ & & $22(11)$ & & $9(4.5)$ & \\
\hline N2 & 152 & $16(10.53)$ & & $12(7.89)$ & & $4(2.63)$ & \\
\hline \multicolumn{8}{|c|}{ Distant metastasis (M) } \\
\hline M0 & 721 & $110(15.26)$ & 0.550 & $80(12.13)$ & 0.88 & $30(4.16)$ & $0.929^{*}$ \\
\hline M1 & 76 & $11(14.47)$ & & $8(10.53)$ & & $3(3.95)$ & \\
\hline \multicolumn{8}{|c|}{ Lymphovascular invasion } \\
\hline Yes & 335 & $47(14.03)$ & 0.451 & $35(10.45)$ & 0.679 & $12(3.58)$ & 0.481 \\
\hline No & 457 & $73(15.97)$ & & $52(11.38)$ & & $21(4.59)$ & \\
\hline Unknown & 5 & & & & & & \\
\hline \multicolumn{8}{|c|}{ Alcohol intake } \\
\hline Ever & 162 & 19 (11.72) & 0.170 & $13(8.02)$ & 0.170 & $6(3.7)$ & 0.755 \\
\hline Never & 635 & $102(16.06)$ & & $75(11.81)$ & & $27(4.25)$ & \\
\hline \multicolumn{8}{|l|}{ Smoking } \\
\hline Ever & 263 & $35(13.31)$ & 0.170 & $24(9.13)$ & 0.226 & $11(4.18)$ & 0.967 \\
\hline Never & 534 & $86(16.1)$ & & 64(11.98) & & $22(4.12)$ & \\
\hline \multicolumn{8}{|c|}{ Colorectal family history } \\
\hline Yes & 48 & $11(22.92)$ & 0.071 & $5(10.42)$ & 0.795 & $6(12.5)$ & $0.016^{*}$ \\
\hline No & 335 & $44(13.13)$ & & $32(9.55)$ & & $12(3.58)$ & \\
\hline Unknown & 414 & & & & & & \\
\hline
\end{tabular}

1 *Fisher's exact test was used 


\section{Table 3 (on next page)}

Correlations between RAS gene mutations and clinicopathological characteristics $(n=813)$. 


\begin{tabular}{|c|c|c|c|c|c|c|c|}
\hline \multirow{2}{*}{ Characteristics } & \multirow{2}{*}{ Number } & \multicolumn{2}{|c|}{$R A S$} & \multicolumn{2}{|c|}{$K R A S$} & \multicolumn{2}{|c|}{$N R A S$} \\
\hline & & Mutation (\%) & $P$ value & Mutation (\%) & $P$ value & Mutation (\%) & $P$ value \\
\hline \multicolumn{8}{|l|}{ Gender } \\
\hline Male & 506 & $221(43.68)$ & 0.105 & $204(40.32)$ & 0.097 & $19(3.75)$ & 0.9 \\
\hline Female & 307 & $152(49.51)$ & & $142(46.25)$ & & $11(3.58)$ & \\
\hline \multicolumn{8}{|l|}{ Age } \\
\hline$<50$ & 100 & $38(38)$ & 0.091 & $37(37)$ & 0.23 & $1(1)$ & $0.161^{*}$ \\
\hline$\geq 50$ & 713 & $335(46.98)$ & & $309(43.34)$ & & $29(4.07)$ & \\
\hline \multicolumn{8}{|l|}{ Location } \\
\hline Right side colon & 181 & $91(50.28)$ & 0.178 & $88(48.62)$ & 0.097 & $3(1.66)$ & 0.164 \\
\hline Left side colon & 189 & 77 (40.74) & & $71(37.57)$ & & $6(3.17)$ & \\
\hline Rectum & 443 & $205(46.28)$ & & $187(42.21)$ & & $21(4.74)$ & \\
\hline \multicolumn{8}{|l|}{ Mucin production } \\
\hline With & 133 & $74(55.64)$ & 0.014 & $73(54.89)$ & 0.002 & $1(0.75)$ & 0.087 \\
\hline Without & 680 & $299(43.97)$ & & $273(40.18)$ & & $29(4.22)$ & \\
\hline \multicolumn{8}{|c|}{ Tumor differentiation } \\
\hline Poor & 138 & $55(39.86)$ & 0.315 & $54(39.13)$ & 0.604 & $1(0.72)$ & 0.093 \\
\hline moderate & 599 & $276(46.08)$ & & $251(41.9)$ & & $28(4.67)$ & \\
\hline Well & 33 & $17(51.52)$ & & $16(48.48)$ & & $1(3.03)$ & \\
\hline Unknown & 43 & & & & & & \\
\hline \multicolumn{8}{|l|}{ Tumor stage } \\
\hline I & 95 & $41(43.16)$ & 0.031 & $35(36.84)$ & 0.023 & $6(6.32)$ & $0.18^{*}$ \\
\hline II & 332 & $170(51.2)$ & & $161(48.49)$ & & $9(2.71)$ & \\
\hline III & 302 & $133(44.04)$ & & $122(40.4)$ & & $14(4.64)$ & \\
\hline IV & 84 & $29(34.52)$ & & $28(34.52)$ & & $1(1.19)$ & \\
\hline
\end{tabular}

Bowel wall invasion $(\mathrm{T})$

\begin{tabular}{llllllll}
$\mathrm{T} 1$ & 21 & $9(42.86)$ & 0.36 & $8(38.1)$ & 0.158 & $1(4.76)$ & $0.36^{*}$ \\
\hline
\end{tabular}




\begin{tabular}{|c|c|c|c|c|c|c|c|}
\hline $\mathrm{T} 2$ & 104 & $40(38.46)$ & & 34 (32.69) & & $6(5.77)$ & \\
\hline $\mathrm{T} 3$ & 336 & $154(45.83)$ & & $146(43.45)$ & & $9(2.68)$ & \\
\hline T4 & 352 & $170(48.3)$ & & $158(44.89)$ & & $14(3.98)$ & \\
\hline \multicolumn{8}{|c|}{ Lymph node metastasis $(\mathrm{N})$} \\
\hline No & 458 & $224(48.91)$ & 0.006 & $209(45.63)$ & 0.079 & $15(3.28)$ & 0.265 \\
\hline N1 & 203 & $88(43.35)$ & & $83(40.89)$ & & $6(2.96)$ & \\
\hline $\mathrm{N} 2$ & 152 & $61(40.13)$ & & $54(35.53)$ & & $9(5.92)$ & \\
\hline \multicolumn{8}{|c|}{ Distant metastasis (M) } \\
\hline M0 & 729 & $343(47.05)$ & 0.048 & $317(43.48)$ & 0.116 & $29(3.98)$ & $0.353^{*}$ \\
\hline M1 & 84 & $30(35.71)$ & & $29(34.52)$ & & $1(1.19)$ & \\
\hline \multicolumn{8}{|c|}{ Lymphovascular invasion } \\
\hline Yes & 339 & $157(46.31)$ & 0.763 & $145(42.77)$ & 0.825 & $14(4.13)$ & 0.623 \\
\hline No & 462 & $209(45.24)$ & & $194(41.99)$ & & $16(3.46)$ & \\
\hline Unknown & 12 & & & & & & \\
\hline \multicolumn{8}{|c|}{ Alcohol intake } \\
\hline Ever & 165 & $67(40.61)$ & 0.128 & $63(38.18)$ & 0.203 & $5(3.03)$ & 0.615 \\
\hline Never & 648 & $306(47.22)$ & & $283(43.67)$ & & $25(3.86)$ & \\
\hline \multicolumn{8}{|l|}{ Smoking } \\
\hline Ever & 283 & $109(38.52)$ & 0.002 & $99(34.98)$ & 0.001 & $10(3.53)$ & 0.863 \\
\hline Never & 530 & $264(49.81)$ & & 247 (46.6) & & $20(3.77)$ & \\
\hline \multicolumn{8}{|c|}{ Colorectal family history } \\
\hline Yes & 48 & $28(58.33)$ & 0.017 & $26(54.17)$ & 0.013 & $3(6.25)$ & $0.178^{*}$ \\
\hline No & 337 & $135(40.95)$ & & $126(37.39)$ & & $9(2.67)$ & \\
\hline Unknown & 428 & & & & & & \\
\hline
\end{tabular}

1 *Fisher's exact test was used 
Table 4(on next page)

Correlations between DNA mismatch repair protein expression deficiency and RAS status $(n=797)$. 


\begin{tabular}{|c|c|c|c|c|c|c|}
\hline \multirow{2}{*}{ MMR status } & \multicolumn{2}{|l|}{$R A S$} & \multicolumn{2}{|l|}{$K R A S$} & \multicolumn{2}{|l|}{$N R A S$} \\
\hline & Mutant/tested cases $(\%)$ & $P$ value & Mutant/tested cases $(\%)$ & $\mathrm{P}$ value & Mutant/tested cases $(\%)$ & $\mathrm{P}$ value \\
\hline dMMR & $54 / 121(44.63)$ & 0.734 & $54 / 121(44.63)$ & 0.635 & $0 / 121(0)$ & $0.009^{*}$ \\
\hline MHL1/PMS2 deficiency & $39 / 88(44.32)$ & 0.725 & $39 / 88(44.32)$ & 0.875 & $0 / 88(0)$ & $0.044^{*}$ \\
\hline MSH2/MSH6 deficiency & $15 / 33(45.45)$ & 0.999 & $15 / 33(45.45)$ & 0.72 & $0 / 33(0)$ & $0.391^{*}$ \\
\hline pMMR & $313 / 676(46.3)$ & & $286 / 676(42.3)$ & & $30 / 676(4.43)$ & \\
\hline
\end{tabular}

$1 \quad$ *Fisher's exact test was used 


\section{Table 5 (on next page)}

Correlations between KRAS gene mutations and clinicopathological characteristics in dMMR tumors $(n=121)$. 


\begin{tabular}{|c|c|c|c|}
\hline \multirow{2}{*}{ Characteristics } & \multirow{2}{*}{ Number } & $K R A S$ & \multirow{2}{*}{$P$ value } \\
\hline & & Mutation (\%) & \\
\hline \multicolumn{4}{|l|}{ Gender } \\
\hline Male & 73 & $31(42.47)$ & 0.555 \\
\hline Female & 48 & $23(47.91)$ & \\
\hline \multicolumn{4}{|l|}{ Age } \\
\hline$<50$ & 29 & $11(37.93)$ & 0.405 \\
\hline$\geq 50$ & 92 & $43(46.74)$ & \\
\hline \multicolumn{4}{|l|}{ Location } \\
\hline Right side colon & 61 & $26(42.62)$ & 0.891 \\
\hline Left side colon & 25 & $12(48)$ & \\
\hline Rectum & 35 & $16(45.71$ & \\
\hline \multicolumn{4}{|l|}{ Mucin production } \\
\hline With & 36 & $20(55.56)$ & 0.116 \\
\hline Without & 85 & $34(40)$ & \\
\hline \multicolumn{4}{|c|}{ Tumor differentiation } \\
\hline Poor & 36 & $10(27.78)$ & $0.099^{*}$ \\
\hline Moderate & 71 & $35(49.3)$ & \\
\hline Well & 4 & $2(50)$ & \\
\hline Unknown & 10 & & \\
\hline \multicolumn{4}{|l|}{ Tumor stage } \\
\hline I & 6 & $2(33.33)$ & $0.277^{*}$ \\
\hline II & 62 & $33(53.2)$ & \\
\hline III & 41 & $15(36.59)$ & \\
\hline IV & 12 & $4(33.33)$ & \\
\hline \multicolumn{4}{|c|}{ Bowel wall invasion (T) } \\
\hline $\mathrm{T} 1$ & 3 & $2(66.67)$ & $0.179^{*}$ \\
\hline
\end{tabular}




$\begin{array}{lcll}\text { T2 } & 5 & 0(0) & \\ \text { T3 } & 59 & 26(44.07) & \\ \text { T4 } & 54 & 26(48.15) & \\ \text { Lymph node metastasis }(\mathrm{N}) & & \\ \text { N0 } & 74 & 38(51.35) & 0.056 \\ \text { N1 } & 31 & 13(41.94) & \\ \text { N2 } & 16 & 3(18.75) & \end{array}$

Distant metastasis (M)

$\begin{array}{lll}\text { M0 } & 110 \quad 50(45.45) & 0.753^{*}\end{array}$

Lymphovascular invasion

\begin{tabular}{lccc} 
Yes & 47 & $21(44.68)$ & 0.927 \\
No & 73 & $32(43.83)$ & \\
Unknown & 1 & & \\
Alcohol intake & & & \\
Ever & 19 & $9(47.37)$ & 0.855 \\
Never & 102 & $46(45.1)$ & \\
Smoking & & & \\
Ever & 35 & $14(40)$ & 0.514 \\
Never & 86 & $40(46.51)$ & \\
Colorectal family history & \\
Yes & 11 & $5(45.45)$ & 0.589 \\
No & 44 & $24(54.55)$ & \\
Unknown & 66 & & \\
\hline
\end{tabular}

*Fisher's exact test was used 
Figure 1

Consort diagram in patient selection.

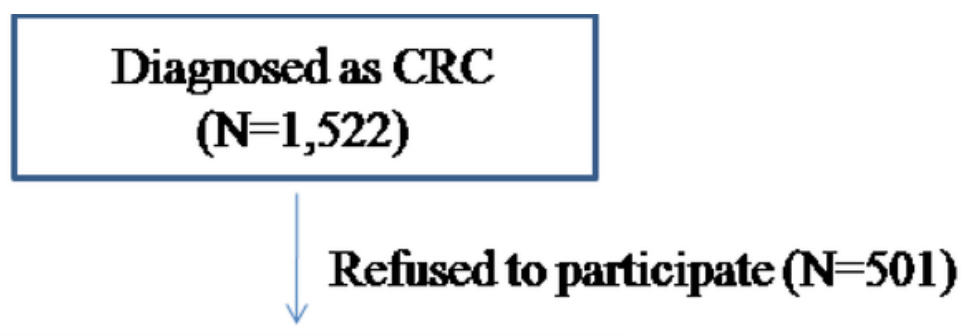

Screened for eligibility

$(\mathrm{N}=1021)$

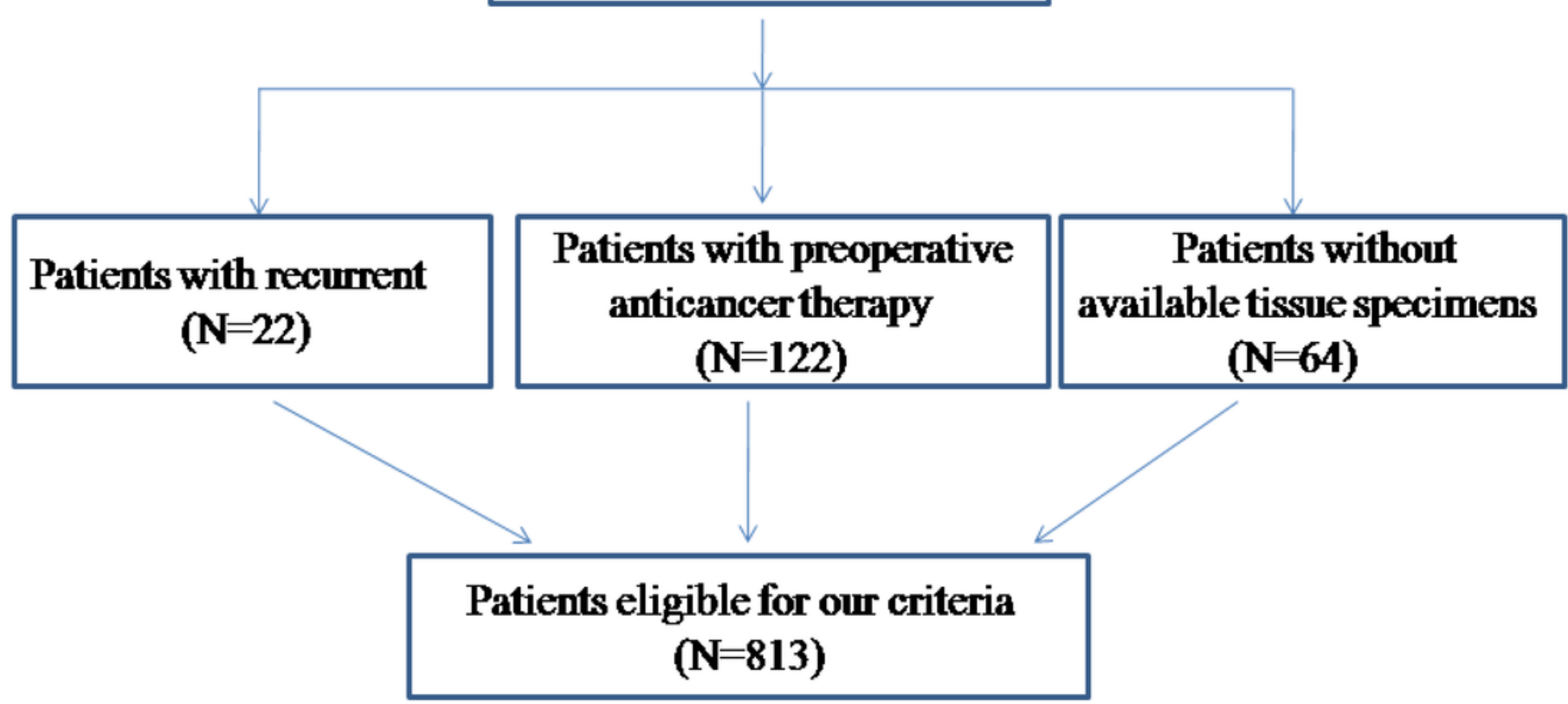


Figure 2

Immunohistochemical staining for mismatch repair proteins in one case of colorectal carcinoma.

Tumor cells with MLH1 (A) and PMS2 (B) expression, and with absent MSH2 (C) and MSH6 (D) expression, which were regarded as deficient MMR. Note the presence of positive staining in stromal cells and lymphocyte serving as internal positive controls.
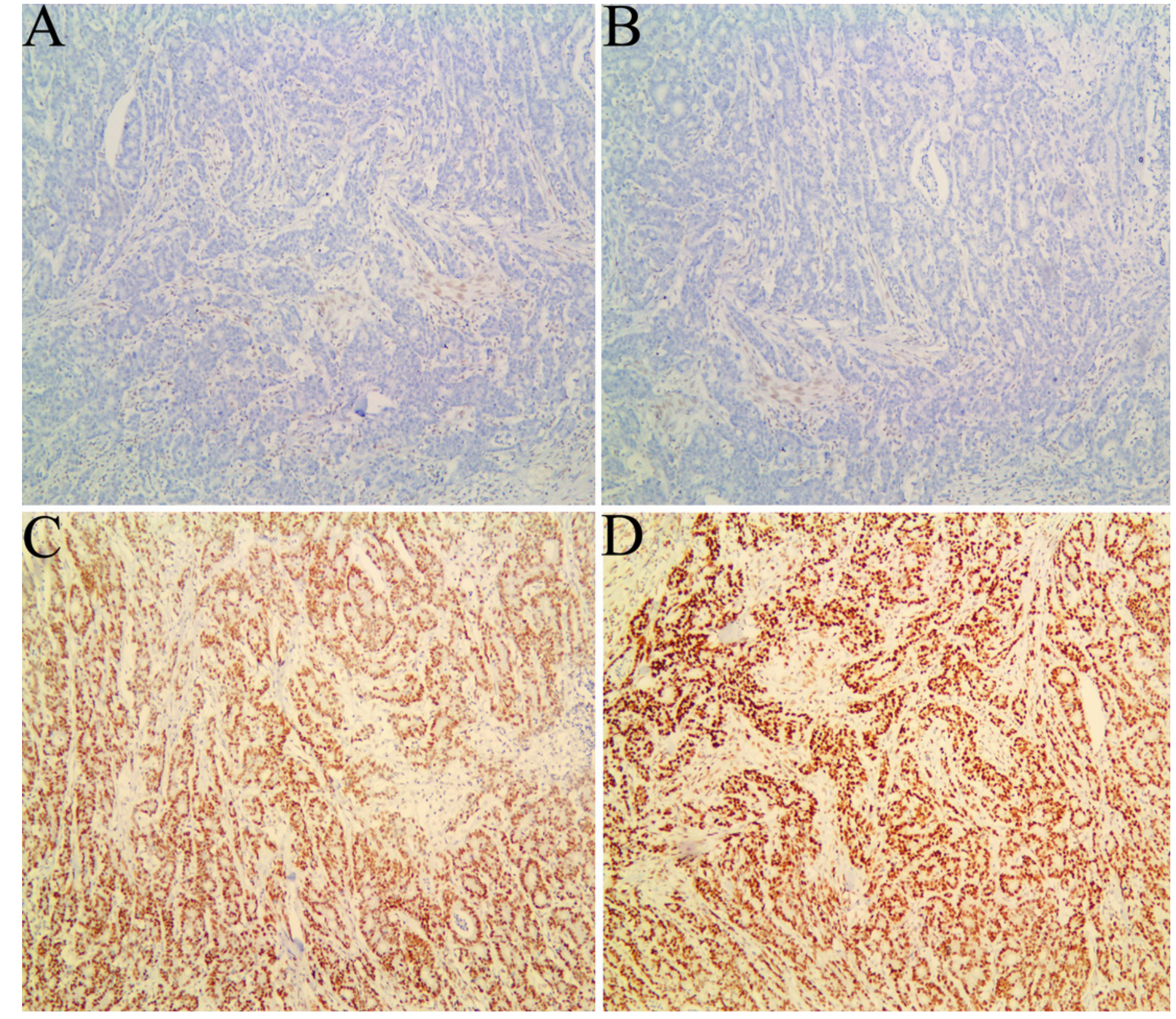


\section{Figure 3}

Survival curves for disease free survival (DFS) and overall survival (OS) in stage I - III colorectal carcinoma according to dMMR or RAS status.

A: Disease free survival (DFS) according to dMMR status; B: Overall survival (OS) according to dMMR status; C: DFS according to KRAS status; D: OS according to KRAS status; E DFS according to NRAS status; F: OS according to NRAS status. 

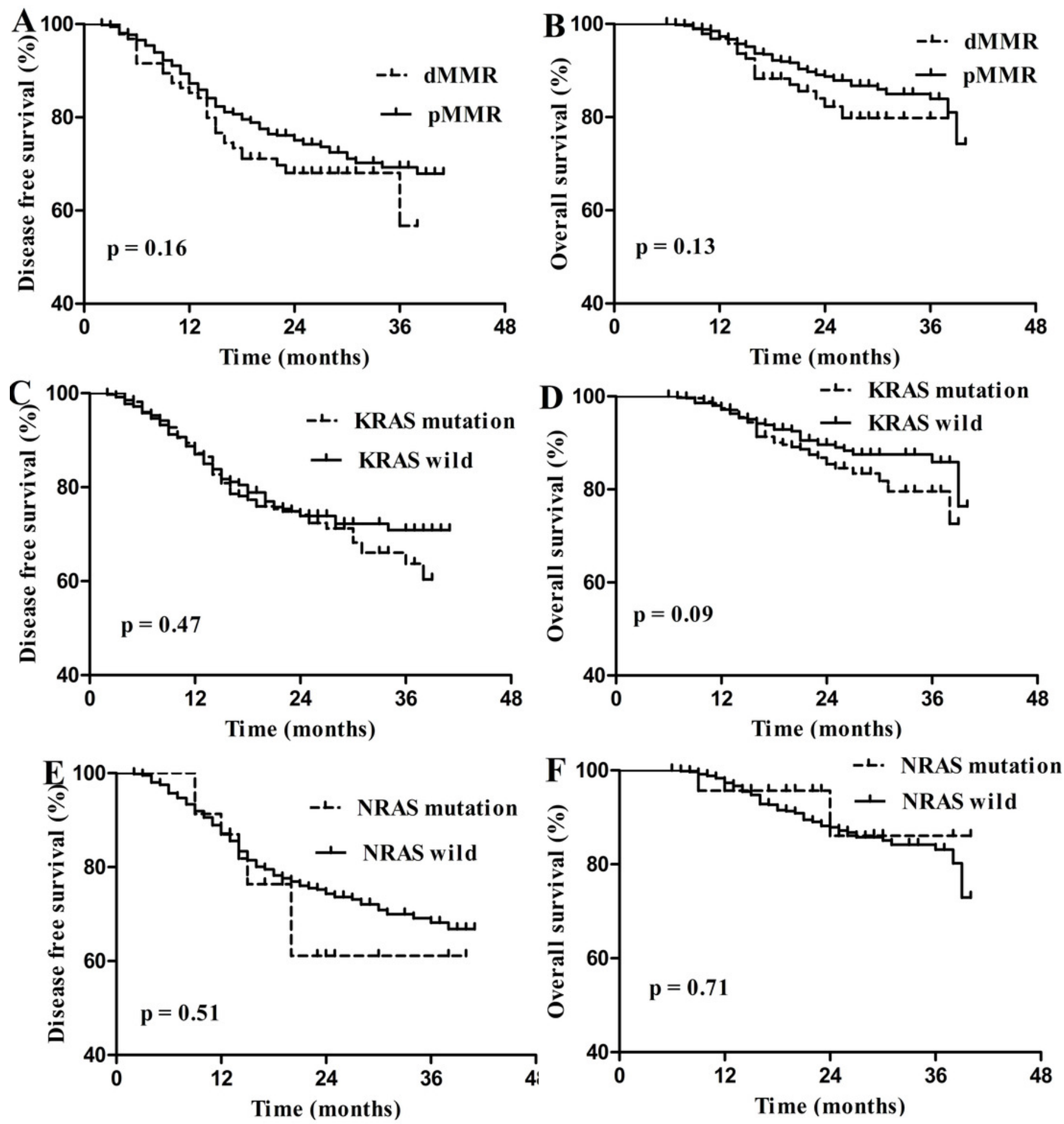
Figure 4

Survival curves for disease free survival (DFS) and overall survival (OS) in stage I - III dMMR colorectal carcinoma according KRAS status.

A: Disease free survival (DFS) according to KRAS status; B: Overall survival (OS) according to KRAS status.
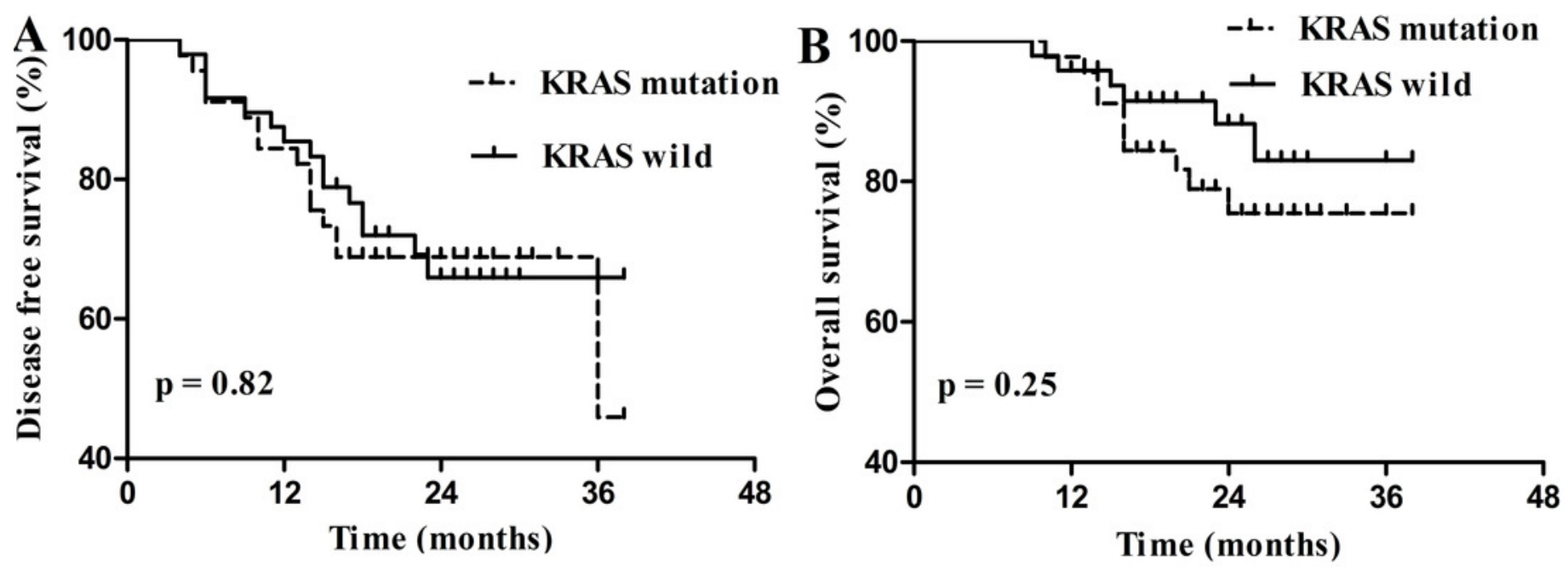